\title{
Assessment of a Loop-Mediated Isothermal Amplification (LAMP) Assay for the Rapid Detection of Pathogenic Bacteria from Respiratory Samples in Patients with Hospital-Acquired Pneumonia
}

\author{
Andrea Vergara ${ }^{1,+}+{ }^{+}$, Hervé Boutal ${ }^{2,+}$, Adrián Ceccato ${ }^{3,4}$, Míriam López $^{1}$, Adrià Cruells ${ }^{5}$, \\ Leticia Bueno-Freire ${ }^{3,4}$, Javier Moreno-Morales ${ }^{6}\left(\mathbb{D}\right.$, Jorge Puig de la Bellacasa ${ }^{1}$, \\ Pedro Castro ${ }^{5,7}\left(\mathbb{D}\right.$, Antoni Torres ${ }^{3,4,5} \mathbb{D}$, Francesc Marco ${ }^{1,6}(\mathbb{D})$, Climent Casals-Pascual ${ }^{1,6}$ and \\ Jordi Vila ${ }^{1,6, *(D)}$ \\ 1 Department of Clinical Microbiology, CDB, Hospital Clínic of Barcelona, University of Barcelona, \\ 08036 Barcelona, Spain; VERGARA@clinic.cat (A.V.); mlopezv@clinic.cat (M.L.); jpuig@clinic.cat (J.P.d.l.B.); \\ fmarco@clinic.cat (F.M.); ccasals@clinic.cat (C.C.-P.) \\ 2 Service de Pharmacologie et Immunoanalyse (SPI), CEA, INRA, Laboratoire d'Etudes et de Recherches en \\ Immunonalyse, Université Paris-Saclay, F-91191 Gif-sur-Yvette, France; Herve.BOUTAL@cea.fr \\ 3 Pulmonary and Critical Care Unit, Respiratory Institute, Hospital Clinic, 08036 Barcelona, Spain; \\ aceccato@clinic.cat (A.C.); bueno@clinic.cat (L.B.-F.); atorres@clinic.cat (A.T.) \\ 4 Biomedical Research Centre in Respiratory Diseases (CibeRes, CB06/06/0028), Institut d'Investigacions \\ Biomèdiques Agust Pi i Sunyer (IDIBAPS), 08036 Barcelona, Spain \\ 5 Department of Medicine, School of Medicine, University of Barcelona, 08036 Barcelona, Spain; \\ acruells@clinic.cat (A.C.); pcastro@clinic.cat (P.C.) \\ 6 ISGlobal, Hospital Clínic-Universitat de Barcelona, 08036 Barcelona, Spain; javier.moreno@isglobal.org \\ 7 Medical Intensive Care Unit, Hospital Clínic, 08036 Barcelona, Spain \\ * Correspondence: jvila@clinic.cat; Tel.: +34-93-2275522 \\ + These authors contributed equally to this work.
}

Received: 5 December 2019; Accepted: 8 January 2020; Published: 11 January 2020

\begin{abstract}
Rapid identification of the causative agent of hospital-acquired pneumonia (HAP) will allow an earlier administration of a more appropriate antibiotic and could improve the outcome of these patients. The aim of this study was to develop a rapid protocol to identify the main microorganisms involved in HAP by loop-mediated isothermal amplification (LAMP) directly from respiratory samples. First of all, a rapid procedure ( $<30 \mathrm{~min}$ ) to extract the DNA from bronchoalveolar lavage (BAL), endotracheal aspirate (EA) or bronchoaspirate (BAS) was set up. A specific LAMP for Staphylococcus aureus, Escherichia coli, Klebsiella pneumoniae, Pseudomonas aeruginosa, Stenotrophomonas maltophilia and Acinetobacter baumannii was performed with the extracted solution at $65^{\circ} \mathrm{C}$ for $30-40 \mathrm{~min}$. Overall, 58 positive BAL and $83 \mathrm{EA} / \mathrm{BAS}$ samples were tested. The limits of detection varied according to the microorganism detected. Validation of the LAMP assay with BAL samples showed that the assay was $100 \%$ specific and $86.3 \%$ sensitive (positive predictive value of $100 \%$ and a negative predictive value of $50 \%$ ) compared with culture. Meanwhile for BAS/EA samples, the assay rendered the following statistical parameters: $100 \%$ specificity, $94.6 \%$ sensitivity, $100 \%$ positive predictive value and $69.2 \%$ negative predictive value. The turnaround time including sample preparation and LAMP was circa $1 \mathrm{~h}$. LAMP method may be used to detect the most frequent bacteria causing HAP. It is a simple, cheap, sensitive, specific and rapid assay.
\end{abstract}

Keywords: loop-mediated isothermal amplification (LAMP); hospital-acquired pneumonia (HAP); diagnostic techniques; respiratory system; critical care 


\section{Introduction}

Hospital-acquired pneumonia (HAP) is the one that presents clinically two or more days after hospitalization and includes ventilator-associated pneumonia (VAP), which is defined as pneumonia that presents after $48 \mathrm{~h}$ with endotracheal intubation [1]. Patients with VAP present longer periods with mechanical ventilation, as well as longer stay in the ICU and in the hospital [2]. It is estimated that approximately $10 \%-40 \%$ of the patients undergoing mechanical ventilation for more than two days will develop VAP [2], with great differences among countries, type of patient, and type of intensive care unit (ICU). The implementation of different preventive strategies enabled a decrease in VAP cases, but it is still a very important problem among ventilated patients [3].

VAP is frequently caused by Gram-negative aerobic bacteria [4-6], such as Pseudomonas aeruginosa, Klebsiella pneumoniae and Acinetobacter spp; while Staphylococcus aureus is the most frequent Gram-positive pathogen [7]. In addition, the VAP can be polymicrobial, which complicates diagnosis and treatment. Regarding viruses, virus herpes simplex (HSV) [8] and cytomegalovirus (CMV) [9] can be reactivated in critical care patients and cause VAP. It should be noted that many of the pathogens causing VAP may present high levels of antibiotic resistance [2,7].

Unfortunately, the diagnosis of VAP is complicated and there is no reliable reference test [10]. The signs and symptoms of pneumonia, such as fever, tachycardia, leukocytosis and purulent secretions, are frequent in patients with mechanical ventilation and are not specific to VAP. Moreover, radiographic changes are difficult to interpret in this group of patients. Therefore, it is necessary to confirm the clinical suspicion of VAP through the microbiological culture of pulmonary secretions. However, the microbiological diagnosis also has several limitations: (1) difficulty to differentiate between colonization and infection; (2) non-homogeneous distribution of the infection in the lung; and (3) negative cultures due to previous empirical antibiotic treatment. Empirical treatment is usually initiated in patients with suspected VAP before having the definitive diagnosis [11], since early and adequate treatment decreases the mortality [12]. However, the indiscriminate administration of antibiotics exposes patients to unnecessary side effects, increases health care costs and favours the appearance of antibiotic resistance. Hence, the importance of knowing if there is an infection or not and the identification of the etiological agent [2].

The application of rapid diagnostic techniques to identify microbial pathogens seems to have a huge impact in the treatment of VAP, reducing inappropriate or unnecessary antimicrobial treatments and mortality in these patients $[13,14]$. Molecular biology techniques have allowed a faster diagnosis of VAP, especially in viral infections. They have the advantage of being faster than culture, allowing the detection of the causative agents even though the patient is receiving antibiotics and being able to quantify the bacterial concentration in the sample. On the other hand, in general they are relatively expensive techniques and detect a limited number of microorganisms.

The reaction based on the loop-mediated isothermal amplification (LAMP), developed in 2000 by Notomi et al. [15], is a rapid, simple, cheap and constant temperature nucleic acid amplification method. This method is very sensitive and specific, and there are numerous publications regarding its use in a wide range of applications [16]. LAMP is characterized by the use of 4 different primers to amplify 6 distinct regions on the target gene, an additional pair of primers to accelerate the reaction and a polymerase with high strand displacement activity in addition to a replication activity. LAMP has been used to identify respiratory pathogens, with promising results $[17,18]$. The purpose of this study was to develop and evaluate a rapid protocol to identify the main microorganisms involved in HAP by LAMP directly from respiratory samples.

\section{Material and Methods}

\subsection{Study Design}

We developed a rapid protocol to identify by LAMP six different bacteria (P. aeruginosa, Acinetobacter baumannii, K. pneumoniae, Escherichia coli, S. aureus and Stenotrophomonas maltophilia) and evaluated 
its performance compared to culture. We used three different types of samples: bronchoalveolar lavage (BAL), endotracheal aspirate (EA) and bronchoaspirate (BAS). Two different protocols were optimized and used to deal with the different consistencies of the samples processed (aspirates being more difficult to work with due to sample thickness).

\subsection{Collection of Samples}

Positive and negative BAL, EA and BAS samples were collected from the Clinical Microbiology Laboratory at the Hospital Clinic of Barcelona (Spain), after being processed for routine techniques. The microbiological result was collected, including Gram stain and culture result. BAL collected during a two-year period (2016/17) and EA/BAS over six months (January to June 2018) were stored at $-80^{\circ} \mathrm{C}$ until use. To standardize the protocol, negative samples were mixed to obtain a homogeneous matrix. Aliquots of this homogeneous negative sample was spiked with different microorganisms and used to determine the limits of detection for each microorganism.

\subsection{Routine Microbiological Methods}

Respiratory samples were collected in sterile containers and transported to the laboratory in less than two hours. Gram staining of the samples in the area of maximal purulence was examined for leukocytes and epithelial cells. Only respiratory samples with Murray-Washington classification degrees of IV (10-25 epithelial cells and $>25$ leukocytes per field using a low magnification lens $(\times 100)), \mathrm{V}(\leq 10$ epithelial cells and $>25$ leukocytes) or VI ( $\leq 10$ epithelial cells and $\leq 10$ leukocytes) were processed for culture. Specimens not fulfilling these criteria were not considered to be representative of distal airways and were not processed for culture.

Good-quality respiratory specimens were quantitatively plated on blood and chocolate agar. Isolated bacteria were identified by matrix-assisted laser desorption/ionization time-of-flight mass spectrometry (MALDI-TOF MS) (Bruker Daltonics, Bremen, Germany). Susceptibility testing was performed according to EUCAST guidelines (Available online: www.eucast.org). Potential pathogenic bacteria included Haemophilus influenzae, Streptococcus pneumoniae, Moraxella catarrhalis, Gram-negative bacilli, P. aeruginosa and S. aureus. Non-potential pathogenic microorganisms included Viridans group streptococci, Neisseria spp, Candida spp, Corynebacterium spp, H. parainfluenzae and coagulase-negative staphylococci and were not considered as clinically significant. These samples were informed as having normal or mixed flora.

\subsection{Extraction of DNA}

Two protocols depending on the type of sample were performed, and they are described in Figure 1. Briefly, samples were concentrated by centrifugation and boiled in DireCtQuant 100W buffer (FrontexBioMed, Ltd./DireCtQuant, Lleida, Spain) to obtain extracted DNA. This extract was later on used for the LAMP test.

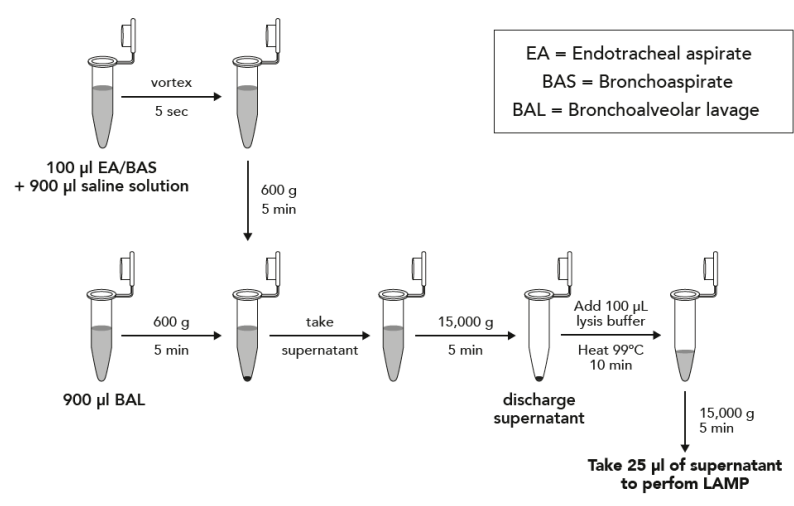

Figure 1. Sample preparation workflow for bronchoalveolar lavage (BAL) and bronchoaspirate/ endotracheal aspirate (BAS/EA). 


\subsection{LAMP Protocol}

Previously described primers [17] were used for P. aeruginosa, A. baumannii, K. pneumoniae, E. coli, S. maltophilia, and S. aureus. The LAMP was performed in $25 \mu \mathrm{L}$ of reaction mixture: $5 \mu \mathrm{L}$ primers $(0.2 \mu \mathrm{M}$ outer, $1.6 \mu \mathrm{M}$ inner and $0.4 \mu \mathrm{M}$ loop primers), $15 \mu \mathrm{L}$ Isothermal Master Mix (Optigene) and $5.0 \mu \mathrm{L}$ of extraction product. Once the reaction mix is ready, gentle vortex and centrifugation must be performed. The reaction was conducted in a Versant kPCR (Siemens, Beersel, Belgium) at $65^{\circ} \mathrm{C}$ for $40 \mathrm{~min}$ for BAL samples and in a Lightcycler ${ }^{\circ} 480$ System (Roche, Sant Cugat del Vallès, Spain) at $65^{\circ} \mathrm{C}$ for $30 \mathrm{~min}$ for EA/BAS. Both protocols can be implemented independently of the thermocycler, but we performed them in two different machines because they were done in different times and changes in laboratory equipment occurred.

\subsection{Determination of the Limits of Detection}

Each microorganism was inoculated into negative BAL samples to a final concentration ranging from $10^{7}$ to $10^{2} \mathrm{CFU} / \mathrm{mL}$. For EA/BAS it was not possible to perform the same study for sensitivity due to the consistency of the samples and the physical impossibility of obtaining homogeneous matrix for all the dilutions. Instead, positive samples were used to perform serial 10-fold dilutions in saline buffer. Final concentration for each dilution was based on the approximate initial concentration determined by culture.

\subsection{Statistical Analysis}

Concordance between culture and LAMP results was studied. Major errors were defined as result discrepancies where the microorganism identified by LAMP was completely different from that identified in culture or the detection of a pathogen when the culture had none. Minor errors were defined as concordant results for the major pathogen identification, but LAMP identified additional microorganisms.

Diagnostic performance was based on sensitivity, specificity, negative- and positive-predictive values, and accuracy defined as described elsewhere $[19,20]$. Accuracy was calculated as concordant results over total number analyzed. Cohen's kappa coefficient was also calculated. Statistical analyses were performed using Stata version 15 (College Station, Texas, USA).

\subsection{Ethical Aspects}

The Ethical Committee of the Hospital Clinic of Barcelona, Spain, approved the study protocol on 9, August, 2016. The study is registered as HCB/2016/0294.

\section{Results}

\subsection{BAL Samples}

The limit of detection of LAMP for the different pathogens tested in BAL was $10^{2} \mathrm{CFU} / \mathrm{mL}$ for S. aureus, E. coli, P. aeruginosa and K. pneumoniae, and $10^{4} \mathrm{CFU} / \mathrm{mL}$ for S. maltophilia and A. baumannii. No cross-reaction was identified using these primers while testing spiked samples with the other microorganisms included in the study. Regarding the evaluation with clinical samples, the concordance between culture and LAMP results is shown in Table 1. A total of 58 positive BAL samples were tested. All major errors happened due to a low concentration of bacterial in the sample, except for one case in which A. baumannii was not detected although with high concentration, and even after repeating the technique. The accuracy of the LAMP assay was of $77.6 \%$ or $87.9 \%$ if the minor errors were considered as a non-true or true result, respectively (Table 2). In addition, calculation of the clinical sensitivity and specificity yielded $100 \%$ (95\%CI; $59 \%$ to $100 \%$ ) specificity, a sensitivity of $86.3 \%$ (95\%CI; $73.7 \%$ to $94.3 \%)$, a PPV of $100 \%$ and a NPV of $50 \%(95 \% \mathrm{CI} ; 33.5 \%$ to $66.6 \%)$ when minor errors where treated 
as a true positive sample. The statistical data considering minor errors as a false positive sample are shown in Table 2.

Table 1. Loop-mediated isothermal amplification (LAMP) results from BAL samples according to the result obtained by culture.

\begin{tabular}{|c|c|c|c|c|c|}
\hline $\begin{array}{l}\text { Microorganisms } \\
\text { Identified by Culture }\end{array}$ & $\mathbf{N}$ & Concordance & Minor Errors & Major Errors & Comments \\
\hline S. aureus & 19 & 15 & $2^{\mathrm{A}, \mathrm{B}}$ & $2^{C, D}$ & $\begin{array}{c}\text { A LAMP: SAUR and SMAL detected } \\
\text { B LAMP: SAUR and PAER detected } \\
\text { (GNB in gram stain) } \\
\text { C,D Culture: Few CFU of SAUR }\end{array}$ \\
\hline P. aeruginosa & 11 & 9 & - & $2^{\mathrm{E}, \mathrm{F}}$ & $\begin{array}{c}\text { E Culture: }<1000 \text { CFU of PAER, LAMP: } \\
\text { SAUR detected } \\
\text { F Culture: }<1000 \text { CFU of PAER, } \\
\text { LAMP negative }\end{array}$ \\
\hline S. maltophilia & 6 & 6 & - & - & - \\
\hline K. pneumoniae & 4 & 2 & - & $2^{\mathrm{G}}$ & G Culture: $<1000$ CFU of KPNE (two cases) \\
\hline E. coli & 3 & 3 & - & - & \\
\hline A. baumannii & 2 & 1 & - & $1^{\mathrm{H}}$ & ${ }^{\mathrm{H}}$ Culture: 100,000 CFU of ABAU \\
\hline Negative & 7 & 6 & $1^{\mathrm{I}}$ & - & $\begin{array}{l}\text { I LAMP: KPNE detected } \\
\text { (GNB in gram stain) }\end{array}$ \\
\hline Mixed flora & 6 & 3 & $3^{\mathrm{J}, \mathrm{K}, \mathrm{L}}$ & - & $\begin{array}{l}\text { J LAMP:PAER detected } \\
\text { K LAMP:SAUR detected } \\
\text { L LAMP:KPNE detected }\end{array}$ \\
\hline TOTAL & 58 & 45 & 6 & 7 & \\
\hline
\end{tabular}

N: number of samples tested by culture and LAMP; SAUR: S. aureus; SMAL: S. maltophilia; PAER: P. aeruginosa; KPNE: K pneumoniae; ECOL: E. coli; ABAU: A. baumannii; GNB: Gram-negative bacilli.

Table 2. Statistics of the use of LAMP to detect pathogens directly from BAL and BAS/EA samples.

\begin{tabular}{ccccc}
\hline & \multicolumn{2}{c}{ Minor Error as Wrong } & \multicolumn{2}{c}{ Minor Error as Right } \\
\cline { 2 - 5 } & Value (\%) & $\mathbf{9 5 \% C I}$ & Value (\%) & 95\%CI \\
\hline BAL & & & & \\
\hline Sensitivity & 76.5 & $62.5-87.2$ & 86.3 & $73.7-94.3$ \\
\hline Specificity & 85.7 & $42.1-99.6$ & 100 & $59-100$ \\
\hline PPV & 97.5 & $86.3-99.6$ & 100 & $89-100$ \\
\hline NPV & 33.3 & $21.9-47.2$ & 50 & $33.5-66.6$ \\
\hline Accuracy & 77.6 & $64.7-87.5$ & 87.9 & $76.7-95$ \\
\hline Kappa coefficient & 43.3 & $17.9-68.8$ & 70.9 & $51.5-90.2$ \\
\hline BAS/EA & & & & \\
\hline Sensitivity & 68.9 & $57.1-79.2$ & 94.6 & $86.7-98.5$ \\
\hline Specificity & 100 & $66.3-100$ & 100 & $66.4-100$ \\
\hline PPV & 100 & $91.3-100$ & 100 & $93.5-100$ \\
\hline NPV & 28.1 & $21.8-35.5$ & 69.2 & $46.5-85.4$ \\
\hline Accuracy & 72.3 & $61.4-81.6$ & 95.2 & $88.1-98.7$ \\
\hline Kappa coefficient & 46.3 & $29.2-63.5$ & 89.7 & $80-99.5$ \\
\hline
\end{tabular}

BAL: bronchoalveolar lavage; BAS: bronchoaspirate; EA: endotraqueal aspirate; PPV: positive predictive value; NPV: negative predictive value; CI: confidence interval.

\subsection{BAS/EA Samples}

The estimated limit of detection of the LAMP assay to detect pathogens directly from BAS or EA samples was $10^{2} \mathrm{CFU} / \mathrm{mL}$ for P. aeruginosa, K. pneumoniae and A. baumannii, $10^{3} \mathrm{CFU} / \mathrm{mL}$ for E. coli, and $10^{4} \mathrm{CFU} / \mathrm{mL}$ for S. aureus and S. maltophilia. No cross-reaction was identified using these primers while testing spiked samples with the other microorganisms included in the study. Regarding the 
evaluation with clinical samples, a total of 83 samples were tested. The accuracy between culture and LAMP results is shown in Table 2 and it was of $95.2 \%$ or $72.3 \%$, respectively when the minor errors where considered as true positives or not. In Table 3, the concordance between the LAMP assay and bacterial culture is shown. All major errors happened due to a low concentration of bacterial in the sample, except for two cases: S. aureus with more than 10,000 CFU/mL in culture and A. baumannii with $300,000 \mathrm{CFU} / \mathrm{mL}$ in culture.

Table 3. LAMP results from BAS/EA samples according to the result obtained by culture.

\begin{tabular}{|c|c|c|c|c|c|}
\hline $\begin{array}{l}\text { Microorganisms } \\
\text { Identified by Culture }\end{array}$ & $\mathbf{N}$ & Concordance & Minor Errors & Major Errors & Comments \\
\hline K. pneumoniae & 13 & 10 & $3^{\mathrm{A}, \mathrm{B}}$ & - & $\begin{array}{l}\text { A LAMP: KPNE and ECOL detected } \\
\text { (two cases) } \\
\\
\text { B LAMP: KPNE and PAER detected }\end{array}$ \\
\hline S. aureus & 10 & 7 & $2^{C, D}$ & $1^{\mathrm{E}}$ & $\begin{array}{l}\text { C LAMP: SAUR and KPNE detected } \\
\text { D LAMP: SAUR and ECOL detected } \\
\text { ECulture: }<1000 \text { CFU of SAUR }\end{array}$ \\
\hline P. aeruginosa & 11 & 9 & $2^{\mathrm{F}}$ & - & $\begin{array}{l}\text { F LAMP: PAER and ECOL detected } \\
\text { (two cases) }\end{array}$ \\
\hline E. coli & 8 & 3 & $5 \mathrm{G}, \mathrm{H}, \mathrm{I}, \mathrm{J}$ & - & $\begin{array}{c}\text { G LAMP: ECOL and PAER detected } \\
\text { H LAMP: ECOL, PAER, SAUR and } \\
\text { SMAL detected } \\
\text { I LAMP: ECOL and KPNE detected } \\
\text { J LAMP: ECOL, PAER and SMAL detected } \\
\text { (two cases) }\end{array}$ \\
\hline S. maltophilia & 2 & 2 & - & - & - \\
\hline Polymicrobial & 10 & 3 & 4 & 3 & See Table S1 in Supplementary Material. \\
\hline Other & 10 & 7 & $3^{\mathrm{K}, \mathrm{L}, \mathrm{M}}$ & - & $\begin{array}{c}\text { K LAMP: ECOL and KPNE detected } \\
\text { L LAMP: PAER detected } \\
\text { M LAMP: PAER, SAUR and SMAL detected }\end{array}$ \\
\hline Mixed flora & 10 & 10 & - & - & - \\
\hline Negative & 9 & 9 & - & - & - \\
\hline TOTAL & 83 & 60 & 19 & 4 & \\
\hline
\end{tabular}

$\mathrm{N}$ : number of samples tested by culture and LAMP; KPNE: K pneumoniae; ECOL: E. coli; PAER: P. aeruginosa; SAUR:

S. aureus; SMAL: S. maltophilia.

Regarding possible amplification inhibitors, a mix of lipidic, hematic, viscous and mucous samples were used and inoculated with the different microorganisms. No evidence of interference was observed in any of these prepared samples.

Most positive results appeared before $30 \mathrm{~min}$, and together with the sample handling time, the results could be obtained within one-hour time.

The sensitivity, specificity, negative and positive predictive values of the LAMP assay to detect pathogens directly from BAS/EA samples are shown in Table 2 . When minor errors were considered as false positive results, the sensitivity was $68.9 \%$ (95\%CI; $57.1 \%$ to $79.2 \%$ ), the specificity was $100 \%$ (95\%CI; $66.4 \%$ to $100 \%$ ), and the PPV and NPV were of $100 \%$ and $28.1 \%$, respectively. However, when minor errors were considered as true positive the statistical indicators were: $94.6 \%(95 \% \mathrm{CI} ; 86.7 \%$ to $98.5 \%$ ) sensitivity, $100 \%$ (95\%CI; $66.4 \%$ to $100 \%$ ) specificity, $100 \%$ PPV and $69.2 \%$ (95\%CI; $46.5 \%$ to 85.4\%) NPV (Table 2).

The time to positivity of the LAMP test was strongly correlated with the number of bacterial $\mathrm{CFU} / \mathrm{mL}$ in culture in EA/BAS samples $(r=-0.71, p<0.01)$ but not in BAL samples (Figure 2). These results suggest that, at least in EA/BAS samples, the time to positivity of LAMP could be used as a semi-quantitative measure. 


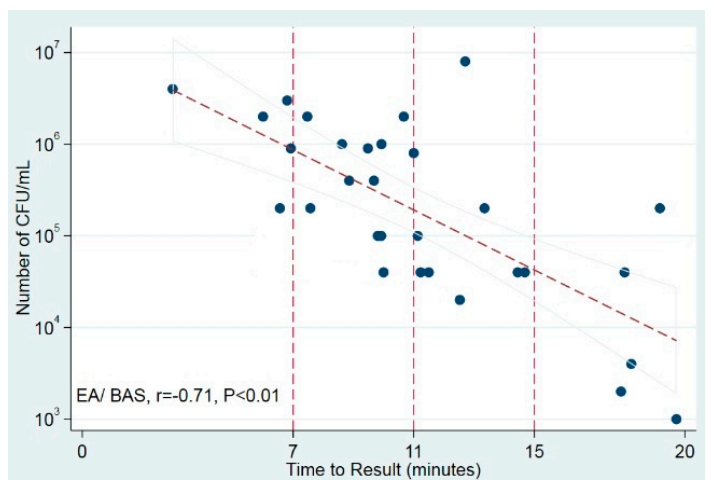

Figure 2. Correlation of time to positivity and bacterial load in culture. Scatter plot shows time to result (in minutes) against number of CFU/mL $(\log 10)$. Trend line displays best fit of all data points and the $95 \%$ CI for the prediction. Vertical reference lines indicate time points. BAS/EA: bronchoaspirate/endotracheal aspirate.

\section{Discussion}

Although new preventive measures have led to a reduction of HAP incidence, it remains associated with important morbi-mortality [21]. Therefore, it is necessary to introduce new methods to improve an early diagnosis. Here, we have evaluated the use of LAMP as a rapid diagnostic tool to identify the main pathogens involved in HAP with promising results.

In this study, we have performed a proof of concept of the used of LAMP to detect the main pathogens causing HAP directly from clinical respiratory samples. We found an overall accuracy between LAMP and culture of $88 \%$ for BAL samples and $95 \%$ for BAS/EA samples. Almost all syndromic tests available to identify pathogens causing respiratory tract infections include virus and atypical bacteria [22], but not many include the major bacterial pathogens causing HAP. Furthermore, rapid identification of the pathogen causing HAP is crucial to improve the patient outcome. In this sense, a multiplex PCR-based syndromic panel including 16 bacterial and one fungal target as well as 22 antimicrobial resistance markers has been evaluated [23-25], showing a sensitivity from $60 \%$ to $90 \%$ and a turnaround time of circa $4 \mathrm{~h}$. In our case, as LAMP is much less affected than PCR by possible inhibitors in the sample [26], in the condition of high bacteria concentration, no automatic nucleic acid extraction is required, and therefore we can reduce turnaround including preparation of the sample and LAMP to around $1 \mathrm{~h}$.

Kang et al. [17] performed a nationwide study in China in which the qLAMP assay was compared with culture to detect eight respiratory bacterial pathogens from sputum, detecting pathogens in 1047 (69.28\%) patients from 1533 qualified patients. They used a kit for the nucleic acid extraction. In our study, although the number of samples included is limited, we have demonstrated that a LAMP applied to respiratory sample without a strict extraction step is possible.

Cost is also important. We have calculated that the LAMP assay (counting both reagents for nucleic acid extraction and LAMP together with plastic material) to detect the six pathogens causing HAP in this study will cost EUR 12.

LAMP may be useful then as a complementary tool to culture, allowing rapid identification of the microorganism causing the infection. In addition, a semi-quantitative approach can be used extrapolating the time to result with the $\mathrm{CFU} / \mathrm{mL}$ in BAS and EA. In BAL, the data that we had were not sufficient to get a significant result (data not shown). If the quantification is under $10^{2}-10^{3} \mathrm{CFU} / \mathrm{mL}$, the LAMP will probably not provide a positive result, but in general the culture result will be considered as colonization in these cases. Therefore, every positive LAMP result should be taken into consideration, always taking into account the Gram stain, quality of samples and clinical situation of the patient. Culture should not be avoided in any case and LAMP could be implemented as a complement to accelerate the diagnosis of HAP. 
Furthermore, it also seems promising for the detection of resistance genes [27,28]. Pathogen identification and potential antibiotic resistance is possible with LAMP, both more rapidly identified $(1 \mathrm{~h})$ than with a time consuming ( 16 to $24 \mathrm{~h}$ ) classical phenotypic method. Furthermore, it could be even faster when applied directly to samples [29].

In conclusion, the LAMP method may be used to detect the most frequent bacteria causing HAP. It is a simple, cheap, sensitive, specific, and rapid (circa one hour) assay. Multiplexing targets may facilitate the implementation of this technique in routine laboratories. Each laboratory must adapt the targets according to its epidemiology.

Supplementary Materials: Supplementary Materials can be found at http://www.mdpi.com/2076-2607/8/1/103/s1. Table S1. LAMP results from polymicrobial BAS/EA samples according to the result obtained by culture.

Author Contributions: Conceptualization, A.V., Adrián Ceccato, J.P.d.l.B., P.C., A.T., F.M. and J.V.; Data curation, A.V.; Formal analysis, A.V., C.C.-P. and J.V.; Investigation, A.V., H.B. and A.C. (Adrián Ceccato); Methodology, A.V., H.B., M.L., A.C. (Adrià Cruells) and L.B.-F.; Supervision, A.V., J.V.; Validation, A.V., H.B., M.L. and J.M.-M.; Writing—original draft, A.V.; Writing—review \& editing, A.V., H.B., A.C. (Adrián Ceccato), M.L., A.C. (Adrià Cruells), L.B.-F., J.M.-M., J.P.d.I.B., P.C., A.T., F.M., C.C.-P. and J.V. All authors have read and agreed to the published version of the manuscript.

Funding: This work was supported by Ajut a la Recerca "Clínic-La Pedrera" 2016 (PEP:HB-16-JF-VG-C) and from the Instituto de Salud Carlos III, Subdirección General de Redes y Centros de Investigación Cooperativa, Ministerio de Economía y Competitividad, Spanish Network for Research in Infectious Diseases (REIPI RD16/0016/0010) and was co-financed by European Development Regional Fund "A way to achieve Europe". This work was also supported by award 2017 SGR 0809 from the Agència de Gestió d'Ajuts Universitaris i de Recerca of the Generalitat de Catalunya.

Conflicts of Interest: The authors declare no conflict of interest.

\section{References}

1. Kohbodi, G.N.A.; Noor, A. Pneumonia, Ventilator-Associated. [Updated 2018 November 18]. In StatPearls [Internet]; StatPearls Publishing: Treasure Island, FL, USA, January 2019. Available online: https://www.ncbi. nlm.nih.gov/books/NBK507711/ (accessed on 14 January 2019).

2. Li Bassi, G.; Ferrer, M.; Marti, J.D.; Comaru, T.; Torres, A. Ventilator-Associated Pneumonia. Semin. Respir. Crit. Care Med. 2014, 35, 469-481.

3. Torres, A.; Niederman, M.S.; Chastre, J.; Ewig, S.; Fernandez-Vandellos, P.; Hanberger, H.; Marin, K.; Li Bassi, G.; Luna, C.M.; Martin-Loeches, I.; et al. International ERS/ESICM/ESCMID/ALAT guidelines for the management of hospital-acquired pneumonia and ventilator-associated pneumonia: Guidelines for the management of hospital-acquired pneumonia (HAP)/ventilator-associated pneumonia (VAP) of the European Respiratory Society (ERS), European Society of Intensive Care Medicine (ESICM), European Society of Clinical Microbiology and Infectious Diseases (ESCMID) and Asociación Latinoamericana del Tórax (ALAT). Eur. Respir. J. 2017, 50, 1700582. [PubMed]

4. Aykac, K.; Ozsurekci, Y.; Basaranoglu, S.T. Future Directions and Molecular Basis of Ventilator Associated Pneumonia. Can. Respir. J. 2017, 2017, 2614602. [CrossRef] [PubMed]

5. Chi, S.Y.; Kim, T.O.; Park, C.W.; Yu, J.Y.; Lee, B.; Lee, H.S.; Kim, Y.I.I.; Lim, S.C.; Kwon, Y.S. Bacterial pathogens of ventilator associated pneumonia in a tertiary referral hospital. Tuberc. Respir. Dis. 2012, 73, 32-37. [CrossRef] [PubMed]

6. Injac, V.; Batranovic, U.; Matijasevic, J.; Vukoja, M.; Hadnadjev, M.; Bukumiric, Z.; Trajkovic, G.; Jankovic, S. Etiology and resistance patterns of bacteria causing ventilator-associated pneumonia in a respiratory intensive care unit. Vojn. Pregl. 2017, 74, 954-962. [CrossRef]

7. Ferrer, M.; Difrancesco, L.F.; Liapikou, A.; Rinaudo, M.; Carbonara, M.; Li Bassi, G.; Gabarrus, A.; Torres, A. Polymicrobial intensive care unit-acquired pneumonia: Prevalence, microbiology and outcome. Crit. Care 2015, 19, 450. [CrossRef] 
8. Bouza, E.; Giannella, M.; Torres, M.V.; Catalán, P.; Sánchez-Carrillo, C.; Hernandez, R.I.; Muñoz, P.; Marañón, G. Task Force for Pneumonia. Herpes simplex virus: A marker of severity in bacterial ventilator-associated pneumonia. J. Crit. Care 2011, 26, 432.e1-432.e6. [CrossRef]

9. Osman, N.M.; Sayed, N.M.; Abdel-Rahman, S.M.; Hamza, S.A.; Abd al Aziz, A.A. The impact of cytomegalovirus infection on mechanically ventilated patients in the respiratory and geriatric intensive care units. Egypt J. Chest Dis. Tuberc. 2014, 63, 239-245. [CrossRef]

10. Klompas, M. Does this patient have ventilator-associated pneumonia? JAMA 2007, 297, 1583-1593. [CrossRef]

11. Kalanuria, A.A.; Zai, W.; Mirski, M. Ventilator-associated pneumonia in the ICU. Crit. Care 2014, 18, 208. [CrossRef]

12. Herkel, T.; Uvizl, R.; Doubravska, L.; Adamus, M.; Gabrhelik, T.; Htoutou Sedlakova, M.; Kolarc, M.; Hanulikc, V.; Pudovac, V.; Langovad, K.; et al. Epidemiology of hospital-acquired pneumonia: Results of a Central European multicenter, prospective, observational study compared with data from the European region. Biomed. Pap. 2016, 160, 448-455. [CrossRef] [PubMed]

13. Roberts, K.L.; Micek, S.T.; Juang, P.; Kollef, M.H. Controversies and advances in the management of ventilator associated pneumonia. Expert Rev. Respir. Med. 2017, 11, 875-884. [CrossRef] [PubMed]

14. Millot, G.; Voisin, B.; Loiez, C.; Wallet, F.; Nseir, S. The next generation of rapid point-of-care testing identification tools for ventilator-associated pneumonia. Ann. Transl. Med. 2017, 5, 451. [CrossRef]

15. Notomi, T.; Okayama, H.; Masubuchi, H.; Yonekawa, T.; Watanabe, K.; Amino, N.; Hase, T. Loop-mediated isothermal amplification of DNA. Nucleic Acids Res. 2000, 28, E63. [CrossRef]

16. Dhama, K.; Karthik, K.; Chakrabort, S.; Tiwari, R.; Kapoor, S.; Kumar, A.; Thomas, P. Loop-mediated Isothermal Amplification of DNA (LAMP): A New Diagnostic Tool Lights the World of Diagnosis of Animal and Human Pathogens: A Review. Pak. J. Biol. Sci. 2014, 17, 151-166. [CrossRef] [PubMed]

17. Kang, Y.; Deng, R.; Wang, C.; Deng, T.; Peng, P.; Cheng, X.; Wang, G.; Qian, M.; Gao, H.; Han, B.; et al. Etiologic Diagnosis of Lower Respiratory Tract Bacterial Infections Using Sputum Samples and Quantitative Loop-Mediated Isothermal Amplification. PLoS ONE 2012, 7, e38743. [CrossRef] [PubMed]

18. Petrone, B.L.; Wolff, B.J.; DeLaney, A.A.; Diaz, M.H.; Winchell, J.M. Isothermal Detection of Mycoplasma pneumoniae Directly from Respiratory Clinical Specimens. J. Clin. Microbiol. 2015, 53, 2970-2976. [CrossRef] [PubMed]

19. Altman, D.G.; Bland, J.M. Diagnostic tests. 1: Sensitivity and specificity. BMJ 1994, 308, 1552. [CrossRef] [PubMed]

20. Altman, D.G.; Bland, J.M. Diagnostic tests 2: Predictive values. BMJ 1994, 309, 102. [CrossRef]

21. Li Bassi, G.; Senussi, T.; Aguilera, E. Prevention of ventilator-associated pneumonia. Curr. Opin. Infect. Dis. 2017, 30, 214-220. [CrossRef]

22. Torres, A.; Lee, N.; Cilloniz, C.; Vila, J.; Van der Eerden, M. Laboratory diagnosis of pneumonia in the molecular age. Eur. Respir. J. 2016, 48, 1764-1778. [CrossRef] [PubMed]

23. Jamal, W.; Al Roomi, E.; AbdulAziz, L.R.; Rotimi, V.O. Evaluation of Curetis Unyvero, a Multiplex PCR-Based Testing System, for Rapid Detection of Bacteria and Antibiotic Resistance and Impact of the Assay on Management of Severe Nosocomial Pneumonia. J. Clin. Microbiol. 2014, 52, 2487-2492. [CrossRef] [PubMed]

24. Kunze, N.; Moerer, O.; Steinmetz, N.; Schulze, M.H.; Quintel, M.; Perl, T. Point-of-care multiplex PCR promises short turnaround times for microbial testing in hospital-acquired pneumonia-An observational pilot study in critical ill patients. Ann. Clin. Microbiol. Antimicrob. 2015, 14, 33. [CrossRef] [PubMed]

25. Ozongwu, C.; Personne, Y.; Platt, G.; Jeanes, C.; Aydin, S.; Kozato, N.; Gant, V.; O’Grady, J.; Enne, V.I. The Unyvero P55 'sample-in, answer-out' pneumonia assay: A performance evaluation. Biomol. Detect. Quantif. 2017, 13, 1-6. [CrossRef]

26. Kaneko, H.; Kawana, T.; Fukushima, E.; Suzutani, T. Tolerance of loop-mediated isothermal amplification to a culture medium and biological substances. J. Biochem. Biophys. Methods 2007, 70, 499-501. [CrossRef]

27. Vergara, A.; Zboromyrska, Y.; Mosqueda, N.; Morosini, M.I.; García-Fernández, S.; Roca, I.; Cantón, R.; Marco, F.; Vila, J. Evaluation of a Loop-Mediated Isothermal Amplification-Based Methodology to Detect Carbapenemase Carriage in Acinetobacter Clinical Isolates. Antimicrob. Agents Chemother. 2014, 58, 7538-7540. [CrossRef] 
28. Garcia-Fernandez, S.; Morosini, M.I.; Marco, F.; Gijón, D.; Vergara, A.; Vila, J.; Ruiz-Carbajosa, P.; Cantón, R. Evaluation of the eazyplex(R) SuperBug CRE system for rapid detection of carbapenemases and ESBLs in clinical Enterobacteriaceae isolates recovered at two Spanish hospitals. J. Antimicrob. Chemother. 2015, 70, 1047-1050. [CrossRef]

29. Zboromyrska, Y.; Vergara, A.; Cosgaya, C.; Verger, G.; Mosqueda, N.; Almela, M.; Pitart, C.; Roca, I.; Marco, F.; Vila, J. Rapid detection of $\beta$-lactamases directly from positive blood cultures using a loop-mediated isothermal amplification (LAMP)-based assay. Int. J. Antimicrob. Agents 2015, 46, 355-356. [CrossRef]

(C) 2020 by the authors. Licensee MDPI, Basel, Switzerland. This article is an open access article distributed under the terms and conditions of the Creative Commons Attribution (CC BY) license (http://creativecommons.org/licenses/by/4.0/). 